\title{
Pastores e trabalhadores agrícolas na Ática nos períodos arcaico e clássico
}

\author{
ANDRÉ LEONARDO CHEVITARESE \\ Departamento de História \\ Universidade Federal do Rio de Janeiro
}

RESUMO: Partindo de uma discussão do conceito de camponês, pretende-se analisar o espaço rural ático nos períodos arcaico e clássico, tendo como fio condutor as figuras do pastor e do trabalhador agrícola.

PALAVRAS-CHAVE: Khóra Ática; camponês; pastor; trabalhador agrícola.

Partindo das definições de Rodney Hilton, Geoffrey de Ste. Croix (1983, p. 210-211) caracteriza camponês e campesinato a partir de sete pontos básicos:

1. Os camponeses (principalmente cultivadores), sejam eles proprietários ou não, possuem os meios de produção agrícola pelos quais subsistem. Eles proporcionam a sua própria manutenção através de seus esforços produtivos e coletivamente eles produzem mais do que o necessário para a sua própria subsistência e reprodução;

2. Eles não são escravos;

3. A maneira pela qual eles ocupam a terra pode variar significativamente: eles podem ser proprietários independentes, arrendatários ou inquilinos;

4. Eles trabalham suas propriedades essencialmente como unidades familiares, basicamente com o trabalho familiar, porém ocasionalmente com o uso restrito de escravos ou de trabalho assalariado;

5. Eles estão normalmente associados em unidades maiores do que a família, comumente em aldeias;

6. Os trabalhadores dependentes (tais como artífices, trabalhadores ligados à construção ou transporte e mesmo pescadores) que têm suas origens e permanecem entre os camponeses podem ser eles próprios considerados camponeses;

7. Eles sustentam as classes sobrepostas pelas quais são explorados em maior ou menor graus, especialmente os donos de terra, usurários, habitantes da cidade e os órgãos do Estado, aos quais eles pertencem e nos quais podem ter ou não direitos políticos.

Os sete pontos esboçados acima podem ser aplicados aos ágroikoi áticos. Estes pontos permitem estabelecer algumas importantes observações. Elas serão discutidas em separado, mantendo a ordem dos tópicos esboçados acima. 
Quanto à participação coletiva dos camponeses produzindo mais do que o necessário para a sua subsistência e reprodução (primeiro ponto), encontra-se uma idéia rapidamente levantada pelo autor, mas que, infelizmente, não conhecerá aprofundamento posterior ao longo da sua obra. De Ste. Croix (1983, p. 186) fala sobre um tipo de assistência mútua envolvendo os agricultores. Os seus exemplos, no entanto, advêm basicamente do mundo romano. Apesar da documentação antiga grega ter produzido poucos casos sobre este tipo de ajuda, o autor praticamente os ignorou. Eles estão associados com as regras da boa vizinhança, da solidariedade e da reciprocidade (Chevitarese, 1998, p. 49-52).

Acerca das variações significativas na forma de o camponês ocupar a terra, podendo ele ser proprietário independente, arrendatário ou inquilino (terceiro ponto). Muito embora este item englobe perfeitamente bem a condição do camponês frente à terra, convém enfatizar que no caso ateniense, em particular, no período clássico, o ágroikos caracterizava-se marcadamente por ser proprietário fundiário (Wood, 1989). O autor deste artigo conhece apenas um caso, em toda a documentação antiga grega, de o camponês ser um inquilino. A referência em questão aplica-se a um meteco (Chevitarese, 2001, p. 83-89, em especial p. 88). Este dado não é garantia, pelo fato de ser único, de que se trata de um caso raro e isolado.

De Ste. Croix (1983, p. 53, 115, 134) parece suficientemente convencido que o camponês conta basicamente com a mão-de-obra da sua própria família para realizar as diferentes atividades agrícolas (quarto ponto). Isto não implica, na visão do autor (1983, p. 114, 144, 505), que o trabalho escravo não estivesse presente na agricultura. Ele irá insistir (1983, p. 112-116, em especial p. 114-115) que este tipo de mão-de-obra é característico dos médios e, principalmente, dos grandes proprietários fundiários atenienses, estes últimos, vistos como absenteístas. Muitos deles irão ter supervisores (ephitrophoi) que podem ser escravos, libertos (1983, p. 140, 145, $180,505)$ ou mesmo cidadãos (1983, p. 181-182). De Ste. Croix constata, por outro lado, que o trabalho assalariado livre era pouco importante na Antigüidade e, particularmente, no mundo grego. Ele mostra $(1983$, p. 112, 113, 179, 217, 505) que o seu emprego estava quase que restrito à época de pico na agricultura, caracterizando este tipo trabalho como sazonal. Das questões tratadas por De Ste. Croix neste ponto, duas precisam ser vistas com uma certa cautela: de imediato, o papel da escravidão agrícola. De fato, o autor tem razão quando associa este tipo de escravidão aos médios e grandes proprietários fundiários. As evidências documentais acerca das atividades desempenhadas pelos escravos nas terras dos atenienses não são especificadas, salvo, porém, em uma única ocasião'; a segunda questão diz respeito ao binômio pico agrícola / trabalho assalariado livre. Considerando que a agricultura ática apresentava ao longo do ano vários picos agrícolas, onde a mão-de-obra livre era altamente exigida, o camponês e a sua família, além trabalharem na sua própria terra, podem ter encontrado oportunidades de trabalho nas propriedades fundiárias dos ricos. Esta atividade paralela permitiria à família camponesa complementar a sua renda (Chevitarese, 1998, p. 52-56). Esta segunda questão sugere, portanto, a necessidade de inclusão de um ponto a mais na definição de Rodney Hilton, qual seja: os camponeses podem ser utilizados (como foram na pólis ateniense) como trabalhadores assalariados, nas épocas de pico agrícola, nas propriedades fundiárias dos ricos.

Sobre a vida do camponês na aldeia (quinto ponto), apesar de reconhecê-la como a unidade característica da khóra, De Ste. Croix infelizmente não dá detalhes da sua importância para a sociedade políade grega, nem discute o papel que ela desempenhou na forma- 
ção sócio-política e econômica do cidadão camponês. Constata-se, uma vez mais, a sua opção (de Ste. Croix, 1983, p. 221) em discutir um determinado problema sob a perspectiva da cultura romana, no caso específico, o papel das kómai no Baixo Império. Os dois pontos não aprofundados pelo autor situam-se hoje, na historiografia antiga grega, como altamente polêmicos. De imediato, questiona-se o lugar de residência do camponês: ele habitaria na aldeia ou na sua propriedade rural? Esta questão remete para o tipo de assentamento rural ático: disperso ou nucleado? Estas duas questões recebem tratamentos diferenciados na historiografia. O próprio autor deste artigo buscou, recentemente, interferir neste debate, assumindo não um dos lados da polêmica, mas propondo a coexistência dos dois modelos de assentamentos rurais na Ática ${ }^{2}$. A discussão sobre o tipo de assentamento - fosse ele nucleado, disperso ou mesmo ambos concomitantemente -, aponta para uma outra questão: como se daria a participação política do cidadão-camponês na pólis ateniense? Muito embora o material que permita ao pesquisador responder esta questão seja altamente fragmentário, é possível compreender como se deu esta participação, bem como as relações envolvendo os espaços urbano e rural na Ática (Chevitarese, 1999a, p. 91-114). Estes dados sugerem um adendo no quinto ponto proposto por Rodney Hilton: apesar de os camponeses estarem associados em unidades maiores do que a família, comumente em aldeias, eles não precisam habitar, de forma permanente, nas kómai.

Verifica-se, por fim, a constatação do autor (1983, p. 42-46, 114-120, 211) de que os camponeses foram explorados pela classe proprietária (sétimo ponto). De Ste. Croix (1983, p. 141,213) chama atenção, no entanto, para o fato de a democracia ateniense ter desenvolvido mecanismos que atenuaram e, ao mesmo tempo, protegeram os cidadãos mais humildes (os próprios camponeses estariam aí incluídos) da ação dos cidadãos mais ricos. Estes mecanismos suavizaram, mas não impediram que a exploração ocorresse nas muitas relações existentes na pólis grega, entre as quais, destacam-se: cidade / campo; cidadão rico / cidadão pobre; grande proprietário fundiário / camponês. Nestes binômios o primeiro elemento obteve larga vantagem sobre o segundo (1983, p. 13, 112-113, 134) ${ }^{3}$.

Definido conceitualmente o camponês e, em particular, a sua utilização para o caso antigo grego, buscar-se-á aplicá-lo (enquanto instrumento de análise) em dois grupos específicos de habitantes rurais: o pastor e o trabalhador agrícola. Antes, porém, de uma análise detalhada enfocando estes dois habitantes do espaço rural ático, seria oportuno inserir alguns dados introdutórios acerca do tratamento dispensado pela documentação antiga grega ao camponês.

Verifica-se, na documentação, uma posição extremamente preconceituosa na hora de descrever o rústico. Ele é apresentado como sendo um homem grosseiro (Teofrasto. Os Caracteres 4,7; 4,11-12; 4,16), ignorante (Aristófanes. As Nuvens 627-631), desprovido de qualquer refinamento social (Aristófanes. As Vespas 1120-1537), que não gosta de política e que procura se manter distante das novidades e dos costumes da ásty, por acha-los muito diferentes do seu campo (Teofrasto. Os Caracteres 4,8; Aristófanes. Os Acarnenses 33-39; As Nuvens 43-52. 372). Aristóteles (A Política 1328b 40-1329a 2, 1329a 25-27, 1330a 2627) chega mesmo a afirmar que os agricultores (georgoí) não deveriam ser considerados cidadãos, mas, escravos. Esta caracterização deve ser vista com cautela, na medida em que os responsáveis por estabelecê-la são autores oriundos das camadas mais abastadas da po- 
pulação, muitas vezes situados no espaço urbano, o que não quer dizer que eles não tivessem interesses na khóra ática.

Deve ser observado, no entanto, que os textos antigos e as imagens dos vasos áticos apresentam sempre o camponês envolvido em algum tipo de trabalho, sugerindo que a sua vida fosse cercada de poucos recursos, possuindo muito pouco tempo para o lazer político (Aristóteles 1318b 13, 1319a 31-32) e frequientando as assembléias apenas quando os assuntos em pauta lhe diziam respeito (Finley, 1985, p. 119). Convém, neste momento, estabelecer aqui uma observação, qual seja: o fato de o camponês estar permanentemente envolvido com o trabalho duro e pesado não deve ser entendido, da nossa parte, como os autores antigos gregos gostariam que fossem, como um distanciamento do ágroikos ático da participação nos assuntos da sua comunidade - tanto no âmbito local (dêmos), quanto no territorial (pólis). Ele era dotado de um conhecimento político, o qual não foi obtido nos círculos formais e elitistas dos kaloí k'agathoí, mas através da sua participação efetiva nos assuntos referentes à pólis. Esta educação política, tão distante da vida cotidiana das sociedades contemporâneas, permitiu-lhe um engajamento nos assuntos internos da sua comunidade políade (para uma discussão, ver: Finley, 1988, p. 17-53).

Estes mesmos textos antigos deixam transparecer, também, uma interessante questão, qual seja: a reciprocidade entre os camponeses áticos, principalmente entre vizinhos, amigos e parentes (Chevitarese, 1998). Esta relação envolvia o empréstimo de dinheiro, não sendo praticamente mencionada a presença de juros, de utensílios agrícolas - tais como o arado, o cesto, a foice, o saco - e de grãos.

O pastor, sendo um homem livre (Lísias 20,11) ${ }^{4}$, insere-se no grupo dos camponeses, já que ele apresenta algumas características comuns aos ágroikoi: ele proporciona a sua própria manutenção através do seu esforço produtivo e coletivo; a sua origem, inserção (sócio-política e econômica) e circulação restringem-se basicamente, mas não exclusivamente, aos limites do espaço rural onde estão localizadas as terras de pastagens (isto é, no interior da aldeia, nas fronteiras da pólis e nas áreas montanhosas); ele é objeto de intensa exploração não apenas pelas elites fundiárias que o mantém, através da remuneração, nos limites da subsistência, como, também, pela ótica do binômio cidade / campo, onde o primeiro elemento da relação leva enorme vantagem sobre o segundo.

A vida do pastor parece ter sido marcada por uma singularidade do resto da sociedade (Burford, 1993, p. 152-56). Este elemento singular pode ser observado na forma como ele é descrito e nas discussões políticas que lhe foram relacionadas.

Muito embora a documentação enfatize mais a criação de animais do que os próprios pastores (Amouretti, 1979, p. 155), ela o descreve como sendo portador de traços simples, com algumas peças de vestuário típicas compondo o seu visual: o gorro (ver fichas 1, 8, 9a, 9b, 10, 11, 12), o manto (ver fichas 1, 8, 9a, 9b, 10, 11, 12), as peles (Teofrasto. Os Caracteres 4,15; Aristófanes. As Nuvens 72; Menandro. Díscolos 415), a vara (ver fichas 1, 8, 12) e um tipo de sapato muito barulhento (Teofrasto. Os Caracteres 4,4,4,17). Ele pode também ser associado com ou sem o rebanho (ver fichas 1, 7, 8, 9, 12; Teofrasto. Os Caracteres 4,8, 4,11 ). Estes elementos ajudam a reforçar o quanto era simples o seu padrão de vida e a sua estreita ligação com o universo rural. Esta caraterização pode explicar, como bem observou Amouretti $(1979,155)$, o porquê dos historiadores não se interessarem pelos pastores. 
Aristóteles (A Política 1291b 17-28, 1292b 25-35, 1296b 25-1297a 8, 1317b 23-25, 1318b 6-1319a 19) considera esta situação bastante interessante sob o ponto de vista político: depois de tecer um elogio à democracia dos agricultores e daqueles que possuem uma propriedade fundiária média, este filósofo constata que, no interior da comunidade agrícola, a melhor espécie de democracia é a dos pastores. Aristóteles (A Política 1319a 20-24, 3138) observa que eles, por estarem dispersos ao longo do território, não possuem tempo, nem desejo de participar de uma assembléia. Aplica-se, no interior desta questão, o significativo exemplo fornecido por Sófocles (Édipo Tiranos vv. 1132-139). No diálogo entre os pastores, o aspecto da singularidade fica evidenciado na fala do emissário de Corinto, ele mesmo, um antigo pastor:

"Não me admira, senhor! Mas embora ele não me conheça, eu o ajudarei a se lembrar claramente; porque eu sei bem que ele está ciente que quando ficávamos na região do Citerão, ele com dois rebanhos e eu com um, eu permaneci em companhia deste homem por três períodos de seis meses cada, da primavera até o surgimento de Arcturo; e quando o inverno vinha, eu dirigia o meu rebanho de volta para o seu estábulo e ele conduzia os dele para os currais de Laios [...]."

A passagem deixa transparecer não apenas um longo intervalo de tempo (segundo a passagem, cada período seria de seis meses) em que o pastor permanecia distante do domínio rural (Amouretti, 1986, p. 213), como também uma falta de definição clara entre as fronteiras de Corinto e Tebas (a região do monte Citerão). A mesma situação é verificada em outras áreas, como por exemplo: entre Atenas e a Beócia (o problema de Panakton) ou entre Argos e Esparta (a região de Cinuria). Esta imprecisão era um fator de tensão nas áreas fronteiriças das póleis, proporcionando a eclosão de muitas guerras (Platão. As Leis 842e843a; Aristóteles. A Política 1330a 14-18; Munn and Munn, 1989, p. 73-74; Burford, 1993, p. 4, 20; Rihll 1991, p. 107). Os pastores constituíam um dos elementos responsáveis, talvez o mais importante, no acirramento das tensões e conflitos entre as póleis vizinhas, já que o estopim de muitas delas era a busca de terras de pastagem para os rebanhos (Platão. A República 373d; Sartre, 1979, p. 213-224; Burford, 1993, p. 4, 19-20, 153; Hodkinson, 1988, p. 51).

Constata-se, a partir de uma análise sistemática da documentação imagética, uma estreita relação entre a figura do pastor e a do rebanho (fichas 1, 7, 8, 9, 12). De imediato, ela pode ser vista no forte entrelaçamento existente entre o pastor, basicamente se ele for escravo, e o rebanho, já que no caso de venda ou de roubo do segundo, o primeiro normalmente o acompanharia (ver nota 4). Esta associação também pode ser evidenciada no cuidado que o pastor deve ter para com os seus animais (as fichas 1, 7, 12 deixam bem clara esta situação): ele deve ter os olhos e os ouvidos bem atentos para evitar que algum animal se afaste ou se perca do rebanho; ele também deve estar sempre vigilante para evitar que o seu rebanho sofra algum o ataque de animais selvagens. A imagem do lobo, tanto nos textos antigos (Platão. A República 415e-416a; Heródoto 9,93; Mainoldi, 1984, p. 130-139), quanto na própria cerâmica ática (ficha 12), representa bem os perigos que cercam o rebanho nas terras de pastagem, a maioria delas, em regiões fronteiriças e montanhosas, com muita mata 
e caverna (Siebert, 1990, p. 151-161) para o predador se esconder. Platão observa que o cão é o companheiro indispensável do pastor, já que este animal vê e ouve com toda a acuidade (A República 404a), da mesma forma que ajuda a evitar o ataque do lobo ao rebanho ( $A$ República 416a, 440d; Burford, 1993, p. 155; sob o ponto de vista filosófico, a relação pastor (cão) / rebanho exalando também uma forte conotação política, ver: Chevitarese, Vieira e Moura, 1998, p. 261; para um aprofundamento desta questão, ver: Gutzwiller, 1991, p. 66-79).

O trabalhador rural é quem melhor se encaixa no grupo dos camponeses, apresentando praticamente todas as características definidas acima (ver item 1). Ele tem a sua vida atrelada à terra, fazendo com que a sua visão de mundo seja norteada pelos valores rurais. Como já foi observado (ver item 2), há uma tendência, na documentação antiga, em caracteriza-lo como um indivíduo bronco, incapaz de olhar a vida além do horizonte da sua aldeia, não devendo, portanto, ser contado entre os cidadãos.

Imagens, referentes às atividades desenvolvidas pelo trabalhador agrícola, são raríssimas na cerâmica antiga grega. Há um total de cinco cenas datadas do final do período arcaico. Todas elas estão inseridas no estilo ático de figuras negras. Uma análise, compreendendo-as conjuntamente, permite identificar dois grupos distintos nas imagens de aragem dos campos: 1. denominado aqui de padrão, refere-se aos elementos básicos ou invariáveis; 2. formado por personagens e temas que complementam o grupo padrão.

O primeiro grupo é composto por dois temas: o trabalhador que conduz os animais de tiro (fichas 18, 19, 20, 21, 22) e a junta de bois (fichas 18, 19a, 20, 22), de burros (ficha 19 b) ou um cachorro (ou seriam dois cães? - ficha 21) que puxa o arado.

O segundo grupo é formado por temas complementares e variados: o semeador (fichas 19, 20,22); outros trabalhadores rurais (ficha 19); personagens vestidos que observam todas as atividades (ficha 19); o fim da jornada de trabalho (ficha 19); e a caça ao cervo (ficha 22).

Buscar-se-á analisar a interação entre estes dois grupos, tomando como ponto de partida um exame geral das cenas contidas nos vasos áticos.

Convém estabelecer, de imediato, três observações:

1. o território ático, no período clássico, tinha uma extensão de $2600 \mathrm{~km}^{2}$, dos quais mais de $1000 \mathrm{~km}^{2}$ eram cobertos por montanhas. Estima-se que o total de área arável na Ática fosse de 566 a $809 \mathrm{~km}^{2}$ (Chevitarese, 2001, p. 47-48);

2. o tamanho das propriedades fundiárias variava significativamente em Atenas: as terras associadas aos ricos situavam-se entre 18 e 27 hectares - não deve ser perdido de vista, porém, que essas propriedades estavam fragmentadas ao longo do território; o tamanho das terras relacionadas com os pobres girava em torno de 1,8 hectares, sendo que muitos dos tetas possuíam bem menos do que essa área (Chevitarese, 2001, 158-161);

3. as imagens dos vasos parecem descrever situações que perpassam o cotidiano do espaço rural ateniense, em particular, daquelas áreas mais propícias ao desenvolvimento agrícola.

Partindo destas observações, verificam-se dois aspectos significativos: as imagens trabalhadas pelos pintores como sendo típicas da paisagem rural ateniense; não obstante, o 
uso de animais de tiro, do arado e de vários tipos de trabalhadores rurais deixam transparecer que elas estão associadas às propriedades fundiárias dos ricos. Estas fazendas estavam situadas nas poucas áreas de planície situadas no território ático, cujas terras eram as mais valorizadas e propícias ao desenvolvimento agrícola, em especial, à cultura dos cereais (Chevitarese, 2001, p. 53-61).

Buscando integrar os dois grupos descritos acima, constatam-se alguns elementos fornecidos pelos pintores, os quais deveriam mesmo fazer parte do ferramental e da técnica agrícola aplicados nos períodos arcaico e clássico ateniense. $\mathrm{O}$ trabalhador, que conduz a junta de animais, aparece em todas as imagens segurando uma vara. Ela deve ser vista como um instrumento indispensável para que ele realize plenamente a sua função. Constata-se, também, que a forma como o trabalhador segura o arado não varia nas cenas. Assim, ele sempre mantém uma das mãos no cabo do arado, enquanto que, com a outra, ele segura a vara utilizada para conduzir os animais de tiro. A maneira como se dá o atrelamento do arado à junta de animais também não muda nas cenas (para um detalhamento do arado antigo, ver: Amouretti, 1986, p. 81-93, especialmente p. 87; Jardé, 1979, p. 19-20). Quanto ao uso de cães para puxar o arado, não deve ser de todo inverossímil, conforme observou Kampmann-Platt (1939, p. 418). As implicações deste uso, porém, podem ser vistas no enorme esforço que o condutor faz sobre o arado, talvez mesmo como forma de compensar o uso de um animal não apropriado para este tipo de tarefa. O semeador, pelo menos em duas cenas, realiza o percurso no sentido inverso daquele feito pelo condutor da junta de animais (Durand, 1986, p. 182). Isto implica dizer, ele joga as sementes no sulco que foi aberto pelo arado.

A ficha 19, aquela que mais detalhes dá dos trabalhos de aragem e de semeadura dos campos, aponta a presença de outros trabalhadores agrícolas. Há aquele que se utiliza de um instrumento manual, uma espécie de picareta (Amouretti, 1986, p. 93-100, em especial p. 95; Jardé, 1979, 20). Dois personagens estão postados na frente dos animais de tiro, cabeças voltadas para trás, em direção aos animais e ao arador. Eles não realizam qualquer atividade na cana A forma como os seus braços estão representados, porém, dá a sensação de que eles estão "constante movimento". Há o que carrega fardos. Outros indivíduos aparecem vestidos na cena, em flagrante contraste com os demais trabalhadores agrícolas que estão nus. Duas possibilidades podem ser admitidas: 1) o proprietário, juntamente com os seus filhos, inspecionando diretamente os trabalhos realizados no seu campo, o que parece ser pouco provável; 2) supervisores (ephitrophoi) que acompanham cotidianamente os trabalhos realizados no campo, sendo os responsáveis pela ligação entre a propriedade rural e o patrão absenteísta, localizado na cidade (Chevitarese, 2001, p. 110). Esta possibilidade parece ser a mais provável. A presença da charrete, transportando duas grandes ânforas, pode sugerir uma marcação de tempo, estabelecendo o fim dos trabalhos agrícolas naquele dia. Sobre a atividade da caça - um tema por demais atrelado ao universo oligárquico - perpassar com as terras agrícolas, além de ser um tema bem desenvolvido por Xenofonte ( $A$ Caça 4,9; $5,12 ; 5,15 ; 5,34 ; 8,2 ; 9,17)$, sugere, como bem observou Durand $(1986,186)$, o avanço das áreas de cultivo sobre o espaço selvagem. É bastante visível, neste sentido, a ausência de uma linha demarcação separando claramente os espaços da cultura, entendido aqui como as terras agrícolas, e do selvagem, assinalado pela presença do caçador e dos animais como cervo, gafanhoto, lagartos e tartaruga. 
As imagens de pastores e de aragem dos campos, quando acrescidas de outros temas presentes na khóra Ática - como a criação de animais -, os quais são trabalhados pelos pintores nos vasos áticos de figuras negras e vermelhas, ajudam a conhecer um pouco mais os elementos constituintes do espaço rural ateniense nos períodos arcaico e clássico.

De imediato, a presença de árvores é um indicativo, muito embora ela não seja a única (para uma discussão mais aprofundada, ver: Chevitarese, 2001, 197-245), para definir as cenas como pertencentes ao espaço rural (fichas 5, 6, 13a, 13b, 15).

O espaço rural ateniense possuía um bom número de animais de criação doméstica (Tucídides 2,14; Garnsey, 1989, p. 93), como burro, jumento e mula (fichas 15, 13a, 14, 16, 19a, 19b), touros e vacas (fichas 5, 6, 7, 12, 13b, 18, 19a, 20, 21a, 22), ovelhas, cabras e bodes (fichas 1, 2, 4, 8, 9a, 9b), porcos (ficha 17), cachorros (21b) e aves, como galináceos e gansos. Como observou Gallant (1991, p. 124), mesmo os agricultores mais pobres, se pudessem, tentariam manter umas poucas ovelhas, bodes, um ou dois burros, porcos (sobre o moderado número de porcos na Ática, ver: Jameson, 1988, p. 97) e uma junta de bois para puxar o arado.

Não deixa de ser interessante, no entanto, o fato de o cavalo não estar entre os animais mencionados acima. Esta ausência pode ser explicada pelo arreio antigo que tornava o cavalo inadequado para puxar cargas pesadas, como, também, pelo grande consumo de forragens que este animal consumia, principalmente, se comparado com os demais animais de tiro (Isager e Skydsgaard, 1992, p. 85-86). Deve ser acrescentada, aos fatores mencionados, uma interessante questão, qual seja: a manutenção do cavalo era custosa, tornando-a acessível somente aos homens ricos (Xenofonte. O Chefe da Cavalaria 1,9; 1,11-12; As Rendas 4,8; Aristóteles. A Política 1289b 35-36, 1321a 8-13; Tucídides 6.12,2; Aristófanes. A Paz 135-139; As Nuvens 12-35; Hodkinson, 1988, p. 63-64; Spence, 1993, p. 183, 191 193 e Apêndice 4; Chevitarese, 2001, p. 55).

A presença do burro, da mula ou da junta de bois não implicava diretamente um maior tempo de lazer ou uma diminuição do trabalho do camponês. Uma parte das suas atividades, como, por exemplo, limpeza das ervas daninhas, poda, enxerto ou a colheita, não poderia ser realizada através do emprego destes animais. Assim, no dia a dia, a enxada e / ou a picareta continuaria a ser a companheira inseparável do árduo camponês ático (Platão. A República 370c; Gallant, 1991, p. 124; Osborne, 1987, p. 16, 41).

A falta de pastos (Burford, 1993, p. 122, 146) e o alto preço do boi (Gallant, 1991, p. 124) podem ter tornado o custo de manutenção deste animal muito elevado, deixando apenas os médios e grandes proprietários fundiários em condições de mantê-los. A sua criação teria sido moderada em Atenas (Hodkinson, 1988, p. 65; Jameson, 1988, p. 94, 97, 99). Esta pólis, muito provavelmente, importava estes animais de outras regiões gregas, tais como, Beócia, Eubéia, Mégara e do Peloponeso (Jameson, 1988, p. 97).

Burros, mulas e jumentos eram usados basicamente no transporte de produtos no interior das grandes póleis. A mula foi também empregada nos transportes de longa distância (Isager e Skydsgaard, 1992, p. 104; para o transporte de longa distância, não especificando porém, o tipo de animal, ver: Tucídides 7.28,1; Diodoro da Sicília 12.80,3;). A junta de bois era usada com muito mais freqüência nos trabalhos pesados, como aragem dos 
campos e o transporte de materiais de construção (Aristófanes. Os Pássaros 582; Aristóteles. A Política 1252b 5; Platão. A República 370d-e; Isager e Skydsgaard, 1992, p. 89; Jameson, 1988, p. 96).

Não apenas o trabalho agrícola e o transporte justificavam a criação destes animais. Eles eram vitais para a economia familiar. O estrume animal era de grande importância para os diferentes tipos de culturas agrícolas (Xenofonte. Econômico 20,10; Aristófanes. Os Acarnenses 1022-1026; ver, também: Hodkinson, 1988, p. 49-50; Isager e Skydsgaard, 1992, p. 111; Burford, 1993, p. 122-124, 136-137; Osborne, 1987, p. 36-37, 47), muito embora, o excremento humano também tenha sido utilizado como fertilizante pelos agricultores (Owens, 1983, p. 44-50). O gado proporcionava, além disto, a carne e o couro, os caprinos forneciam a carne e o leite, os porcos e as lebres davam a carne e as aves proporcionavam não apenas carne, como, também, ovos (para os vários tipos de carnes consumidas, ver: (de lebre) Aristófanes. Os Acarnenses 520, 878, 1006, 1110; Os Cavaleiros 1192-1199; As Vespas 709; A Paz 1150, 1196, 1312; (de aves) Aristófanes. Os Acarnenses 872-878; (carne em geral) Aristófanes. Os Cavaleiros 654-662; Os Acarnenses 739-835; Pseudo-Xenofonte. A Constituição dos Atenienses 2,9; Platão. A República 373c; Glotz, 1946, p. 48; Gallant, 1991, p. 119-120, 125; Isager e Skydsgaard, 1992, p. 91, 93; Burford, 1993, p. 146; Bertrand e Brunet, 1993, p. 173; com relação ao baixo consumo do leite de vaca e a preferência pelos leites da ovelha e da cabra, ver: Isager e Skydsgaard, 1992, p. 89-91; sobre a criação de aves, ver: Aristóteles. História dos Animais 558b 8; Isager e Skydsgaard, 1992, p. 94-96). Eles também eram utilizados para fins religiosos (Jameson, 1988, p. 87-119). O sacrifício destes animais perpassava todos os níveis da sociedade políade ateniense, desde o indivíduo, passando pela família, grupo de parentesco, a aldeia e chegando até o envolvimento do coletivo, neste caso, a própria pólis (Durand, 1986; Isager e Skydsgaard, 1992, p. 174-177).

Há poucas informações sobre a origem dos animais sacrificados. Levando-se em consideração que eles deveriam ser cuidadosamente selecionados, gozando de uma boa saúde, poderiam ser propostas duas possibilidades: os animais seriam propriedades de alguns templos que, das inúmeras atividades programadas ao longo do ano, passariam a vendê-los aos fiéis, ou poderiam ser propriedades de indivíduos particulares, especialmente homens ricos, que obtinham bons lucros com este tipo de comércio (Gallant, 1991, p. 121-127; Isager e Skydsgaard, 1992, p. 179-180, 191-198).

Constatam-se algumas cenas de cruzamento de animais diretamente associados com a agricultura. Elas aparecem exclusivamente na cerâmica ática de figuras vermelhas (fichas 13a, 14, 15), muito embora, possam ser detectadas referências indiretas ou mesmo indícios desta temática nos vasos áticos de figuras negras. Assim, por exemplo, podem ser lidas as representações de bezerros mamando nas tetas das vacas (fichas 5, 6). Estas representações, além de estarem integradas no panorama rural ateniense, apontam para a própria reprodução e manutenção dos animais de agrícolas, no geral, e dos animais de tiro, no particular. Aristóteles dedica uma atenção especial para estes últimos animais. Pode-se organizar, a partir das suas análises, o seguinte quadro: 


\section{Dados aristotélicos sobre animais de tiro na khóra Ática}

\begin{tabular}{|c|c|c|c|c|}
\hline & $\begin{array}{c}\text { Período de vida } \\
\text { (em anos) }\end{array}$ & $\begin{array}{c}\text { Início da maturidade } \\
\text { sexual (em anos) }\end{array}$ & $\begin{array}{c}\text { Período de prenhez } \\
\text { (em meses) }\end{array}$ & $\begin{array}{c}\text { Momento da cria } \\
\text { (em meses) }\end{array}$ \\
\hline Cavalo $^{1}$ & $18-20$ & 4,5 & 11 & 12 \\
\hline Burro $^{2}$ & + de 30 & 2,5 & 10 & 11 \\
\hline Jumento $^{3}$ & $-\cdots---$ & 7 & 10 & 10 \\
\hline Boi $^{4}$ & 15 & 2 & 9 & 11 \\
\hline
\end{tabular}

Apesar da cobertura do cavalo ser menos laboriosa que a do boi ${ }^{10}$, este último acaba reproduzindo muito mais do que o primeiro. A criação do gado e do cavalo colocava algumas questões, tais como: ambos demandavam pastos, o que não era um problema fácil de ser resolvido na Ática. Mesmo a prática da transumância restringia as poucas áreas de pasto existentes ao uso exclusivo dos próprios habitantes da região ou a alguns indivíduos de fora da comunidade, que por terem desempenhado algum papel relevante no interior desta respectiva sociedade, acabavam sendo agraciados com o privilégio do direito de pastagem (Gallant, 1991, p. 126; Isager e Skydsgaard, 1992, p. 100). A criação de cavalo, por outro lado, além de ser cercada por cuidados especiais, requeria pessoas especializadas ${ }^{11}$ e uma grande quantidade de forragem para alimenta-los. Já o burro e o jumento, apesar de serem espécies gramíneas, satisfaziam-se com uma menor forragem (Isager e Skydsgaard, 1992, p. 87) do que o cavalo e reproduziam por um grande espaço temporal.

Os resultados obtidos até o momento devem ser vistos com cautela. Este cuidado se deve a três fatores básicos: as informações contidas na documentação antiga grega, relativas aos pastores e trabalhadores agrícolas, são esparsas e superficiais; há poucos estudos realizados até o momento sobre o tema em questão; a minha pesquisa de pós-doutorado ${ }^{12}$ está em curso, logo os resultados obtidos não são conclusivos, mas parciais e preliminares.

\section{Notas}

1 - Para uma discussão mais detalhada, ver: Chevitarese, 1999b, p. 75-98.

2 - Sobre os atuais debates historiográficos e para os argumentos do autor, ver: Chevitarese, 1997, p. 65-79.

3 - Sobre a ênfase de trocas assimétricas na sociedade ateniense no período clássico, ver: Millett, 1989, p. 15-47; para um ponto de vista muito próximo daquele exposto por De Ste. Croix, ver: Wood, 1988, p. 56, 127.

4 - Sobre a possibilidade de o pastor ser escravo, ver: Chevitarese, 2001, p. 54, incluindo nota 14.

5 - Verifica-se um detalhe muito interessante, levantado por Erika Simon, na ficha 8 do catálogo do presente trabalho. Esta autora sugeriu que a estação do ano presente na imagem fosse a primavera, não sendo, porém, quente, o bastante, para o pastor retirar o seu pesado manto, mas, já suficientemente tarde no ano, para as ovelhas serem tosquiadas. A análise de Erika Simon é citada por Sparkes, 1985, 23.

6 - Aristóteles. História dos Animais 575b 21-577a 17; com relação à égua, ela vive em média vinte e cinco anos (Aristóteles. História dos Animais 576a 30-576b 1) e está madura sexual- 
mente com a idade de três anos, reproduzindo até os vinte anos. O período em que permanece prenhe é de onze meses, parindo no mês seguinte (Aristóteles. História dos Animais 575b 2426). Ela gera um potro apenas (Aristóteles. História dos Animais 575b 33-576a 1). O filósofo observa, no entanto, que deve existir o intervalo de um ano entre a última cria e um novo cruzamento da égua com o garanhão. Observa também que os melhores potros nascem quando há intervalo de quatro a cinco anos após a última cria da égua (Aristóteles. História dos Animais 575b 27-577a 1).

7 - Aristóteles. História dos Animais 545b 21, 577a 18-577b 4.

8 - Aristóteles. História dos Animais 577b 5-578a 4. O dado referente ao período de vida não foi fornecido, porém Aristóteles (História dos Animais 577b 29-30) observa a existência de um jumento com mais de oitenta anos.

9 - A vaca vive em média quinze anos (Aristóteles. História dos Animais. 575a 31) e é considerada madura sexualmente com a idade de dois anos, reproduzindo até o final de sua vida (Ibidem). 575a 24-25, 30). O período em que permanece prenhe é de nove meses, parindo no mês seguinte (Ibidem. 575a 26). O número de bezerros por cria é um, muito embora, algumas vezes, a vaca possa ter dois (Ibidem. 575a 29-30).

10 - Ibidem. 575b 29-30.

11 - Aristóteles (História dos Animais 577b 13-15) parece sugerir a existência de criadores ou de pessoas especializadas na criação de cavalos. O Próprio emprego do termo i\&ppofovrbion, por parte deste filósofo, ajuda a definir locais específicos para a criação de eqüinos. Sobre o uso deste ver: Ibidem. 576a 20, 576b 3, 25-26.

12 - Esta pesquisa, que conta com uma Bolsa do CNPq, está sendo realizada no Departamento de História da UNICAMP, com a supervisão do Prof. Dr. Pedro Paulo de Abreu Funari.

\section{Referências bibliográficas}

AMOURETTI, M.-C. Le pain et l'huile dans la Grèce Antique. De l'araire au moulin. Besançon: Annales Littéraires de l’Université de Besançon, 1986.

L'iconographie du berger. Les sources grecques, VIIIème-IIIème siècle avant J. C. In: ___ Iconographie et histoire des mentalités. Paris: Éd. du CNRS, 1979, p. 155-167.

BERTRAND, J.; BRUNET, M. Les Athéniens. À la recherche d'un destin. Paris: Armand Colin, 1993.

BURFORD, A. Land and labor in the Greek world. Baltimore and London: The John Hopkins University Press, 1993.

CHEVITARESE, A. L.; VIEIRA, A. L. B.; MOURA, J. F. Os pastores nos documentos antigos gregos. In: DA SILVA, F. C. T. (Org.). História e imagem. Rio de Janeiro: Programa de Pós-Graduação em História Social, 1998, p. 253-262.

CHEVITARESE, A. L. O espaço rural da pólis grega. O caso ateniense no Período Clássico. Rio de Janeiro: Fábrica de Livros, 2001.

. Philaí, dêmoi e escravidão agrícola na Atenas Clássica. Phoînix. Rio de Janeiro, v. 5, p. 75-98, 1999 b.

- Política e cidadania nos dêmoi áticos no Período Clássico. Boletim do Centro de Estudos e Documentação Sobre o Pensamento Antigo. Campinas, v. 7, p. 91-114, 1999a. 
. Parentes, amigos e assalariados livres na agricultura ática no Período Clássico. Phoînix. Rio de Janeiro, v. 4, p. 47-58, 1998.

. Território rural ático no Período Clássico: unidade ou diversidade? Phoînix. Rio de Janeiro, v. 3, p. 65-79, 1997.

DE STE. CROIX, G. E. M. The class struggle in the Ancient Greek world. From the Archaic Age to the Arab conquests. London: Duckworth, 1983.

DURAND, J.-L. Sacrifice et labour en Grèce Ancienne. Essai d'anthropologie religieuse. Paris: La Découverte, 1986.

FINLEY, M. I. A política no Mundo Antigo. Tradução de Álvaro Cabral. Rio de Janeiro: Zahar, 1985.

. Democracia antiga e moderna. Tradução de Waldéa Barcellos e Sandra Bedran. Rio de Janeiro, Graal, 1988.

GALLANT, T. W. Risk and survival in Ancient Greek. Reconstructing the rural domestic economy. Cambridge: Cambridge University Press, 1991.

GARNSEY, P. Famine and food supply in the Graeco-Roman world. Cambridge: Cambridge University Press, 1989.

GUTZWILLER, K. J. Theocritus' pastoral analogies. The formation of a genre. Wisconsin: The University of Wisconsin Press, 1991.

HODKINSON, S. Animal husbandry in the Greek Polis. In: WHITTAKER, C. R. (Ed.). Pastoral economies in Classical Antiquity. Cambridge: The Cambridge Philological Society, 1988, p. 35-74.

ISAGER, S.; SKYDSGAARD, J. E. Ancient Greek agriculture: an introduction. London: Routledge, 1992.

JAMESON, M. H. Sacrifice and animal husbandry in Classical Greece. In: WHITTAKER, C. R. (Ed.). Pastoral economies in Classical Antiquity. Cambridge: The Cambridge Philological Society, 1988, p. 87-119.

JARDÉ, A. Les céréales dans l'Antiquité Grecque. La production. Paris: de Boccard, 1979. KAMPMANN-PLATT, L. Chien tirant la charrue. Peinture d'un vase attique. Revue des Études Grecques. Paris, v. 52, 415-418, 1939.

MAINOLDI, C. L'image du loup et du chien dans la Grèce Ancienne-d'Homère à Platon. Paris: Ophrys, 1984.

MILLETT, P. Patronage and its avoidance in Classical Athens. In: WALLACE-HADRILL, A. Patronage in Ancient Society. London: Routledge, 1989, p. 15-47.

MUNN, M. H.; MUNN, M. L. Z. Studies on the Attic-Boiotian frontier: The Stanford Skoúrta Plain Project, 1985. In: FOSSEY, J. M. (Ed.). Beotia Antigua I. Papers on recent work in Boiotian Archaeology and History. Amsterdam: Gieben, 1989, p. 73-123.

OSBORNE, R. Classical landscape with figures: The ancient greek city and its countryside. London: George Philip, 1987.

OWENS, E. J. The Koprologoi at Athens in the fifth and fourth centuries B.C. In: The Classical Quarterly. Oxford, v. 33, 1, p. 44-50, 1983. 
RIHLL, T. E. Ekthmoroi: partners in crime? In: The Journal of Hellenic Studies. Londres, v. 111, p. 101-127, 1991.

SARTRE, M. Aspects économiques et aspects religieux de la frontière dans les cités grecques.

In: Ktèma. Strasbourg, v. 4, p. 213-224, 1979.

SIEBERT. Imaginaire et images de la grotte dans la Grèce Archaïque et Classique. In: Ktèma. Strasbourg, v. 15, p. 151-161, 1990.

SPARKES, B. A. Aspects of Onesimos. In: BOULTER, C. G. (Ed.). Greek art archaic into Classical. Leiden: Brill, 1985, p. 18-39.

SPENCE. The cavalary of classical Greece. A social and military history. Oxford: Clarendon Press, 1993.

WOOD, E. M. Peasant-citizen and slave. The foundations of Athenian democracy. London \& New York: Verso, 1989.

CHEVITARESE, A. L. Les bergers et les travailleurs agricoles en Attique, aux périodes archaïque et classique. Classica, São Paulo, 13/14, p. 123-144, 2000/2001.

RÉSUMÉ: Provenant d'un débat critique à propos du concept de paysan, on a l'intention d'analyser la superficie rurale attique aux périodes archaïque et classique, ayant comme point de partie les figures du berger et du travailleur agricole.

MOTS-CLÉS: Khóra Attique; paysan; berger; travailleur agricole.

\section{Anexo \\ Catálogo de cenas de pastores e trabalhadores agrícolas na cerâmica ática}

\section{Ficha 1}

Kýathos ático de figuras negras. Paris, Musée du Louvre. Inventário: F 69. Prov. Vulci. Theozotos, Potter.

Bibliografia: Beazley, ABV 349; Webster, POTTER p. 247 (c); Malagardis, IMAGES p. 107, fig. 1a.

Descrição: situado à esquerda da cena, cabreiro barbado, voltado para a direita, veste manto, usa um gorro na cabeça. Ele segura com a mão direita uma vara (ou lança curta?) apoiada no seu ombro direito, enquanto que o seu braço esquerdo está levantado e com 
a mão segura um chicote pronto para ser usado contra o rebanho de cabras. Ele é acompanhado pelos seus cães. À sua frente seguem quatro cabras para a direita, sendo que uma delas, boca aberta, cabeça voltada para trás, na direção do cabreiro, aparenta estar visivelmente agitada.

\section{Ficha 2}

Hidría ática de figuras negras. Londres, British Museum. Inventário: B 328. Prov. Vulci. The Leafless Group.

Bibliografia: CVA, Great Britain, 8, British Museum, 6, pls. 86, 4 e pl. 89, 2; Beazley, ABV 363, 42; Webster, POTTER p. 247 (c); Malagardis, IMAGES p. 107-109.

\section{Descrição:}

(no ombro do vaso) um homem barbado voltado para a direita, nu, com o manto jogado sobre o ombro direito, tenta dominar um bode. As suas mãos estão no dorso do animal que tem a sua cabeça voltada para trás, em direção ao homem. Entre eles estão duas mulheres sentadas sobre tamboretes, vestindo manto e himátion, fitas na cabeça, sendo que aquela situada no lado direito da cena tem o seu braço esquerdo esticado para frente, com a sua mão tocando levemente no pescoço do animal. No extremo esquerdo da cena, um homem barbado, nu, corpo voltado para a esquerda, cabeça virada para trás, movimento das pernas sugerindo que ele está se afastando, observa toda a ação.

\section{Ficha 3}

Taça ática de figuras negras. Londres, British Museum. Inventário: 64.10-7.1724. Prov. Rodes (Camiros?). The Leafless Group. Data: 550-500.

Bibliografia: Beazley, ABV 646, 205; Webster, POTTER p. 247 (c); Malagardis, IMAGES p. 107.

\section{Descrição:}

(medalhão) pastor;

(lados a e b) touros e vacas.

\section{Ficha 4}

Taça ática de figuras negras. Roma, Museo Etrusco Gregoriano Vaticano. Inventário: 330. The Centaur Painter.

Bibliografia: Beazley, ABV 189, 9; Webster, POTTER p. 247 (c); Albizzati, VADV p. 117, pls. 35-36.

Descrição: homem voltado para a esquerda, nu, barbado, manto sobre o braço esquerdo, clava na mão direita persegue um carneiro.

\section{Ficha 5}

Enócoa ática de figuras negras. Bruxelas, Bibliothèque Royale. Inventário: 5. Prov. Vulci. The Painter of London B 620. 
Bibliografia: Beazley, ABV 434, 4; Malagardis, IMAGES p. 107, fig. 1 c.

Descrição: uma vaca situada no centro da cena, voltada para a direita, cabeça virada para trás, observa a sua cria, um bezerro, mamando na sua teta. À esquerda da cena, há uma árvore, enquanto que, na parte superior da cena, aparece uma ave, voltada para a esquerda, voando.

\section{Ficha 6}

Enócoa ática de figuras negras. Boulogne-sur Mer, Musée Comunal. Inventário: 476. The Leagros Group.

Bibliografia: Beazley, ABV 377, 245; Malagardis, IMAGES p. 107; Pfuhl, MALEREI pl. $75, n^{\circ} 282$.

Descrição: no centro da cena está Héracles (verificam-se as presenças da clava, da pele de pantera e da aljava depositada no solo) sentado sobre uma pedra. Entre ele estão duas vacas, uma de cada lado da cena, com seus respectivos bezerros mamando em suas tetas. Nas extremidades da cena estão localizadas duas árvores frutíferas (?) com seus galhos repletos de pássaros. À direita, na parte mais externa, um cão (?) voltado para a esquerda.

\section{Ficha 7}

Ânfora ática de figuras negras. Nova York, Metropolitan Museum. Inventário: GR 529. Red-Line Painter.

Bibliografia: Beazley, ABV 602, 28; Boardman, ABFV fig. 282.

Descrição: homem imberbe (o deus Hermes?), voltado para a esquerda, sentado sobre uma pedra, cabeça coroada, vestindo manto, tem o seu braço direito esticado em direção aos animais, enquanto que a sua mão esquerda, com os seus dedos esticados, está aberta. A sua frente, dois bovinos voltados para a direita (o gado de Apolo?). Eles parecem estar se movimentando, já que as suas patas esquerdas dianteiras estão levantadas. Verificamse ramos de árvore frutífera (há frutos brancos) perpassando todo o fundo da cena.

\section{Ficha 8}

Taça ática, figuras vermelhas. Alemanha, Coleção Privada. Onesimos. Data: 490-480.

Bibliografia: Sparkes, GAAC p. 18-39, plates 26-27; Hornbostel, KA nº 263.

Descrição: pastor descalço, voltado para a direita, usando um manto feito de pele amarrado com um nó no ombro direito, gorro listrado na cabeça, leva a sua recém tosada manada para casa. Ele segura uma vara na mão direita e na mão esquerda uma correia, levando o carneiro ao seu lado. Do animal que vai à frente só são visíveis a cauda e uma parte do seu traseiro.

\section{Ficha 9}

Pelíke ática, figuras vermelhas. Paris, Musée du Louvre. Inv. G. 536. Prov. Nola. The Geras Painter. Data: $480-470$. 
Bibliografia: CVA, France, 12, Musée du Louvre, 8, pl. 45, figs. 5, 7, 11; Beazley, ARV 286, 14; Pottier, VAL p. 289-90; Boardman, ARFV-AP fig. 180; Amouretti, BERGER p. $163,167$.

\section{Descrição:}

(lado a) pastor voltado para a direita, vestindo clâmide, com uma pele de cabra colocada sobre as costas e gorro na cabeça. Ele está montado em um bode, virado também para a direita, tocando uma flauta dupla;

(lado b) pastor voltado para a direita, vestindo clâmide, com uma pele de cabra colocada sobre as costas e gorro de pele na cabeça. Ele está montado em um carneiro, virado também para a direita, tocando uma flauta dupla.

\section{Ficha 10}

Cratera ática, figuras vermelhas. Boston, Museum. Inv. 10185. Prov. Cumes. The Pan Painter. Data: 475-450.

Bibliografia: Amouretti, BERGER p. 166-67.

Descrição: pastor, vestindo túnica e um manto de pele, gorro na cabeça, é perseguido por Pan.

\section{Ficha 11}

Ânfora ática, figuras vermelhas. Berlim. Inv. F 4052. Prov. Locres. Data: quinto século.

Bibliografia: Amouretti, BERGER p. 167.

Descrição: pastor, vestindo túnica e gorro na cabeça, sentado sobre uma rocha, toca flauta diante de um sátiro.

\section{Ficha 12}

Rhytón ático, figuras vermelhas. Nova Iorque, Metropolitan Museum of Art. Inv. 38.11.2. Circle of The Sotades Painter. Data: 470-460.

Bibliografia: Richter, BMMA p. 225-26; Richter, AJA p. 6, figs. 4-5; Richter, ARFVASES p. 111-12, fig. 80; Bérard et Vernant, CITÉ p. 10, fig. 7.

Descrição: pastor, em uma campina, voltado para a esquerda, usando túnica curta, manto (de pele?), sapatos e gorro na cabeça. Ele está sentado sobre uma pedra cuidando de duas vacas que pastam em direções opostas. Há um lobo, parecido com um cachorro, saindo de uma caverna, sobre a qual cai um galho de hera. Este animal parece estar rondando as vacas. Na frente da árvore, localizada no centro da cena, está uma lebre. No lado direito deste animal está um arbusto.

\section{Ficha 13}

Taça ática, figuras vermelhas. Bologna, Museo Civico. Inv. C 175. Prov. Necrópole Etrusca de Certosa. The Dokimasia Painter. Data: 480-475. 
Bibliografia: CVA, Italia, 5, Bologna, Museo Civico, 1, tav. 7, figs. 1, 3; Cloché, CLASSES pl. 13, fig. 5.

\section{Descrição:}

(lado a) homem barbado em pé, voltado para a direita, com um pano em torno do quadril. Ele tem o seu braço esquerdo estendido para frente, sobre um burro itifálico que levanta a cabeça em ato de relinchar. A sua mão direita está próxima da pata traseira direita do animal, possivelmente incitando este animal Há uma corda presa no focinho do burro. À sua frente, presa em uma oliveira (?), encontra-se uma jumenta que parece forçar as suas patas traseiras contra o solo. Ela está em posição de cruzamento;

(lado b) dois touros e uma vaca, voltados para a direita, retornam do pasto. Atrás da vaca está uma oliveira (?).

\section{Ficha 14}

Choús ático, figuras vermelhas. Munique, Museum Antiker Kleinkunst. Inv. 2469. The Class of the Seven Lobster-Claws. data: 475-425.

Bibliografia: CVA, Deutschland, 6, München, Museum Antiker Kleinkunst, 2, tafel 89, fig. 4; Beazley, ARV 971; Beazley, PARA 435.

Descrição: dois burros voltados para a direita se acasalando.

\section{Ficha 15}

Taça ática, figuras vermelhas. Adria, Museo Civico. Inventário: B. 425. Prov. Adria. The Dokimasia Painter. Data: 480.

Bibliografia: CVA, Italia, 28, Adria, Museo Civico, 1, tav. 16, fig. 1b; Beazley, ARV 412, 8.

Descrição: à esquerda da cena, um jovem imberbe, voltado para a direita, braço esquerdo flexionado, a mão um pouco fechada, com a palma voltada para dentro, enquanto que a mão direita está apoiada na cintura. Ele veste um manto, os cabelos são circundados por uma fita e há um bastão, cuja parte superior é recurvado, apoiado no lado esquerdo do seu corpo. O jovem parece estar incitando duas mulas situadas à sua frente. Aquela voltada para a direita, tem a boca aberta, focinho ligeiramente levantado, em ato de relinchar. Há uma árvore localizada atrás desta mula.

\section{Ficha 16}

Taça ática, figuras vermelhas. Boston, Museum of Fine Arts. Inv. 10.199. Prov. Orvieto. The Antiphon Painter. Data: 480.

Bibliografia: Beazley, ARV 337, 26; Caskey and Beazley, AVP vol. II, 42 (144), pl. LXXXI, 4; Cloché, CLASSES p. 23, 85, pl. 37, fig. 1; MFAB 9, 52-53.

Descrição: uma mula, voltada para a esquerda, anda com um fardo em seu dorso. Sobre um tecido, na forma de linhas cruzadas e franjas, está uma sela de madeira, atada por meio de arreio e de uma corda fina presa no final de cada extremo e que passa pelo ventre do animal. Na sela está um 'pacote' listrado, dobrado e amarrado no peitoral e ao redor do 
seu traseiro. A mula está com freios e as rédeas estão amarradas frouxamente no peitoral, com os extremos pendurados. As orelhas estão atentas, o olho esquerdo observa a lateral. A crina está cortada rente, exceto na parte acima e próxima à cabeça e no e no dorso, onde um pequeno tufo é deixado perto da montaria. Duas pequenas tetas são mostradas.

Há duas inscrições: NIKOSTRATOSKALOS e LAKESKALOS

\section{Ficha 17}

Pelíke ática, figuras vermelhas. Cambridge, Fitzwilliam Museum. Inv. 9.17. The Pig Painter. Data: 470-460.

Bibliografia: Beazley, ARV 564, 27; Cloché, CLASSES p. 23, pl. 15,2; Robertson, AVPCA p. 148, figs. 152, 153; Osborne, CLASSICAL capa.

Descrição: dois homens barbudos, voltados para a esquerda, caminham junto com seus porcos. Aquele localizado mais à esquerda da cena, cabeça voltada para trás, gorro de pele, manto preso na altura do pescoço por um broche, tem o braço direito levantado, enquanto que a mão esquerda segura a ponta de um saco localizado nas suas costas. atrás dele está o seu companheiro, pano ao redor da cintura, trazendo no ombro direito uma vara com um cesto preso em cada extremidade. As suas mãos estão segurando a vara, mantendo-a equilibrada. Um porco, voltado para a esquerda, e um leitãozinho, virado para a direita, acompanham-os.

\section{Ficha 18}

Ânfora ática de figuras negras. Londres, Comércio. The Bucci Painter. Data: 525-500.

Bibliografia: SOTHEBY 9.dec.1985, p. 132; Malagardis, IMAGES p. 119, 121, fig. 9c.

\section{Descrição:}

(lado a) arador bardado, voltado para a direita, pílos de lã na cabeça, usando como manto uma pele de animal, segura com a mão direita o cabo (ceirolabivV) do arado e com a outra mão uma vara que tange a junta de bois.

\section{Ficha 19}

Taça ática de figuras negras. Paris, Musée du Louvre. Inventário: F 77.

Bibliografia: CVA, France, 14, Musée du Louvre, 9, pl. 82, 4, 6-10; Foxhall, COUNTRYSIDE p. 106-107, fig. 6.2 a-d; Malagardis, IMAGES p. 117, fig. 7; Bertrand e Brunet, DESTIN p. 175; Amouretti, Pain p. 294, n. 4b, pl. 8; Durand, SACRIFICE p. 182-84, figs. 89 a-d.

\section{Descrição:}

(lado a) no extremo esquerdo da cena, um homem completamente envolto em um manto, voltado para a direita, braço esquerdo (?) esticado para frente. Um outro homem nu voltado para a esquerda, levando nas costas um fardo praticamente desaparecido, salvo por uma pequena ponta ainda visível, que ele segura com as duas mãos. A maneira como 
o seu braço esquerdo está representado ajuda a reforçar a presença do fardo. Um outro homem nu, barbado, voltado para a esquerda, trabalha com um tipo de picareta. Arador nu, voltado para a direita, corpo projetado para frente da haste (e*cevtlh) do arado, segurando com a mão direita o cabo (ceirolabivV) e com a outra mão uma vara. $\mathrm{O}$ movimento que ele realiza com as pernas e os braços visa tanger a junta de bois. À frente dos animais de tiro, um homem nu, voltado para a direita, cabeça e dorso voltados para trás, braços levantados. Próximo a ele, um semeador nu, voltado para a esquerda, tendo a sua cesta apoiada no braço direito, enquanto que a sua mão esquerda está fechada, segurando sementes prontas para serem lançadas no solo. No extremo direito da cena, uma mula (?) voltada para a direita;

(lado b) homem com corpo envolto em um manto, voltado para a direita, segura com a mão direita um bastão. Um outro homem envolto em um manto curto, deixando a parte do seu corpo a vista, voltado para a direita, cabeça e dorso voltado para trás, olha em direção ao companheiro que segura a lança. Um terceiro homem, corpo praticamente oculto atrás dos vasos, voltado para a direita, sentado em uma charrete puxada por duas mulas, segura com um das mãos uma vara. Há duas grandes ânforas com tampas na charrete. Elas provavelmente continham grãos. Na frente dos animais, um homem nu, voltado para a esquerda, cabeça e dorso voltado para trás, braço esquerdo levantado. À sua frente, um outro homem vestido, voltado para a direita, braço esquerdo esticado para frente. No extremo esquerdo da cena, um arador nu, barbado, voltado para a direita, corpo projetado para frente da haste ( $\mathrm{e}^{*}$ cevtlh) do arado, segurando com a mão direita o cabo (ceirolabivV) e com a outra mão uma vara. $\mathrm{O}$ movimento que ele realiza com as pernas e os braços visa tanger a junta de mulas.

\section{Ficha 20}

Taça ática de figuras negras. Londres, British Museum. Inventário: 1906, 12-15, 1. Prov. Camiros (Rodes). The Burgon Group.

Bibliografia: CVA, Great Britain, 2, British Museum, 2, pl. 10, 6 b; Beazley, ABV 90, 7; Amouretti, PAIN p. 294, n. 4a, pl. 8a; Malagardis, IMAGES p. 118, fig. 8a; Durand, SACRIFICE p. 181-82, fig. 88.

Descrição: homem nu, voltado para a direita, conduz uma junta de bois. Ele segura o cabo do arado com a mão direita, enquanto que, na outra mão, ele tem uma vara para usar contra os animais. À esquerda, de costas para o companheiro, um outro homem nu, segurando uma cesta na mão esquerda, deixa cair no solo, da sua outra mão, as sementes.

\section{Ficha 21}

Skýphos ático de figuras negras. The Hague, Gemeente Museum. Inventário: 3.39. Data: 550-500.

Bibliografia: Beazley, Para 87, 23; Malagardis, IMAGES p. 119-20, figs. 9a-b; Durand, SACRIFICE p. 85, figs. 90a, 90b; Kampmann-Platt, CHIEN, p. 415-18. 


\section{Descrição:}

(lado a) camponês nu, voltado para a direita, conduz o arado puxado por dois bois;

(lado b) camponês nu, com um corpo muito mais avantajado que aquele da cena a, voltado para a direita, conduz o arado puxado por um cão (ou seriam dois cachorros?). Este animal tem as duas patas dianteiras levantadas, focinho ligeiramente alongado, seus flancos magros e o rabo longo. Este animal é represenatdo quase que do mesmo tamanho do seu condutor.

\section{Ficha 22}

Taça ática de figuras negras. Berlim, Antikensammlung. Inventário: F 1806. Prov. Vulci (Etrúria). Nicosthenes Painter. Data: 550-500.

Bibliografia: Beazley, ABV 223 (66); Schnapp, CHASSEUR 265, nº 225; Malagardis, IMAGES 116, 118 fig. 8b; Durand, SACRIFICE p. 185-86, fig. 91.

\section{Descrição:}

(medalhão) caçador agachado, braço esquerdo apoiado sobre a coxa esquerda, segura com a mão direita um lagobólon;

(área decorada interna) três jovens nus conduzem seus arados puxados por juntas de bois. Um deles segura com a mão direita o cabo do arado, enquanto que o terceiro tem na mão direita um lança. Pelo menos dois aradores usam lanças para caçar cervos. Um jovem semeador nu, localizado entre um boi e um arador, segura, pela alça, com a mão esquerda, uma cesta que está apoiada na coxa esquerda, enquanto que a sua mão direita, ligeiramente fechada, está segurando sementes prontas para serem lançadas no solo. Há um jovem caçador nu, perna direita levantada, segurando uma lança com a mão direita. Existem, na cena, dois lagartos e partes de um gafanhoto e de uma tartaruga.

Há uma inscrição: NIKOSQENESEPOIESEN.

\section{Abreviaturas utilizadas no Catálogo}

ABFV. BOARDMAN, J. Athenian Black Figure Vases. London: Thames and Hudson, 1991. ABV. BEAZLEY, J. D. Attic Black-Figure Vase-Painters. Oxford: Clarendon Press, 1956.

AJA. RICHTER, G. M. A. American Journal of Archaeology. Nova Iorque, v. 43, p. 6, figs. 4-5, 1939.

ARFV-AP. BOARDMAN, J. Athenian Red Figure Vase - The Archaic Period. London: Thames and Hudson, 1991.

ARFVASES. RICHTER, G. M. A. Attic Red-Figured Vases. New York: Yale University Press, 1946.

ARV. BEAZLEY, J. D. Attic Red-Figured Vase Painters. Oxford: Clarendon Press, $2^{\mathrm{a}}$ ed., 3 vols., 1963. 
AVP. CASKEY, G.; BEAZLEY, J. D. Attic Vase Painting in the Museum of Fine Arts, Boston. London: Oxford University Press, 3 vols., 1931-1963.

AVPCA. ROBERTSON, M. The Art of Vase Painting in Classical Athens. Cambridge: Cambridge University Press, 1992.

BMMA. RICHTER, G. M. A. An Athenian Cup in the Form a Cow's Hoof. In: Bulletin of the Metropolitan Museum of Art. Nova Iorque, v. 33, p. 225-228, 1938.

BERGER. AMOURETTI, M.-C. L'Iconographie du Berger. Les Sources Grecques, VIIIèmeIIIème siècle avant J. C. In: . Iconographie et Histoire des Mentalités. Paris: Edicion du CNRS, 1979, p. 155-167.

CHIEN. KAMPMANN-PLATT, L. Chien Tirant la Charrue. Peinture d'un Vase Attique. In: Revue des Études Grecques. Paris, v. 52, p. 415-18, 1939.

CITÉ. BÉRARD, C.; VERNANT, J.-P. La Cité des Images. Religion et Société en Grèce Ancienne. Paris: Fernand Natan - L.E.P., 1984.

CHASSEUR. SCHNAPP, A. Le Chasseur et La Cité. Chasse et Érotique dans la Grèce Ancienne. Paris: Albin Michel, 1997.

CLASSES. ClOCHÉ, P. Les Classes, Les Metiérs, Le Trafic. Paris: Les Belles Lettres, 1931.

CLASSICAL. OSBORNE, R. Classical Landscape with Figures. The Ancient Greek City and Its Countryside. London: George Philip, 1987.

COUNTRYSIDE. The Greek Countryside, In: SPARKES, B. A. Greek Civilization. An Introduction. Oxford: Blackwell, 1998, p. 99-114.

CVA. Corpus Vasorum Antiquorum.

DESTIN. BERTRAND, J.; BRUNET, M. Les Athéniens. À la Recherche d'un Destin. Paris. Armand Colin, 1993.

GAAC. SPARKES, B. A. Aspects of Onesimos. In: BOULTER, C.G. (Ed.). Greek Art Archaic into Classical. Leiden: E.J.Brill, 1985.

IMAGES. MALAGARDIS, N. Images du Monde Attique à L'Époque Archaique. In: Archaiologike Ephemeris. Atenas, v. 127, p. 95-134, 1988.

KA. HORNBOSTEL, W. et Alli. Kunst der Antike. Mainz-Rhein: Verlag Philipp Von Zaben, 1977.

MALEREI. PFUHL, E. Malerei und Zeichnung der Griechen. München: F. Bruckmann, 1923.

MFAB. Museum of Fine Arts (Boston), Bulletin. Boston, v. 9, p. 52-53.

PAIN. AMOURETTI, M.-C. Le Pain et L'Huile dans la Grèce Antique. De L'Araire au Moulin. Besançon: Annales Littéraires de l’Université de Besançon, 1986.

PARA. BEAZLEY, J. D. Paralipomena. Additions to Black-Figured-Painters and to Attic Red-Figured Vase-Painters. Oxford: Clarendon Press, 2aed., 1971.

POTTER. WEBSTER, T. B. L. Potter and Patron in Classical Athens. London: Methuen, 1972. 
SACRIFICE. DURAND, J.-L. Sacrifice et Labour en Grèce Ancienne. Essai d'Anthropologie Religieuse. Paris: La Découverte, 1986.

SOTHEBY. Catalogue Sotheby's.

VADV. ALBIZZATI. Vasi Antichi Dipint del Vaticano. Roma: P. Sansaini, 1924-1938.

VAL. POTTIER, E. Vases Antiques du Louvre. Paris: Hachette, 1922. 